\title{
Natalizumab treatment in multiple sclerosis: the experience from two Brazilian MS centers
}

\author{
Natalizumabe no tratamento da esclerose múltipla: a experiência de dois centros \\ brasileiros
}

\author{
Enedina Maria Lobato de Oliveira1, Renata Faria Simm², Gorana Dasic ${ }^{3}$, Marilia Mamprim de Morais? \\ Samira Luiza dos Apostolos Perreira², Dagoberto Callegaro²
}

\begin{abstract}
Objective: Analyze the demographics, clinical characteristics, efficacy and safety of natalizumab treatment in Brazilian patients with multiple sclerosis (MS) followed up for at least 12 months, in two tertiary MS care centers in São Paulo. Method: We evaluated the effect of natalizumab treatment on annualized relapse rate and disability progression in 75 patients with MS treated with natalizumab for at least 12 months. A subgroup analysis was performed to evaluate efficacy of natalizumab treatment in patients with Expanded Disability Status Scale $($ EDSS $) \leq 3.0$ vs patients with EDSS $>3$. Results: Patients treated for at least one year with natalizumab showed a $91 \%$ reduction in aRR, as well and an improvement in neurological disability. The impact of natalizumab treatment was greater in patients with EDSS < 3.0 . Overall, natalizumab was safe but one patient developed progressive multifocal leukoencephalopathy. Conclusion: Natalizumab as a third line therapy is safe and efficacious, especially in patients with mild neurological disability.
\end{abstract}

Keywords: natalizumab, multiple sclerosis, disability progression, relapse rate.

\section{RESUMO}

Objetivo: Analisar as características clínicas e demográficas, assim como a eficácia e segurança do tratamento com natalizumabe (usado em terceira linha), por no mínimo 12 meses, em pacientes brasileiros acompanhados em dois centros de tratamento de esclerose múltipla, na cidade de São Paulo. Método: Avaliamos o efeito do tratamento com natalizumabe na taxa anualizada de surto (aRR) e progressão de incapacidade (medida por Expanded Disability Status Scale (EDSS)) em 75 pacientes tratados por, no mínimo 12 meses. Realizamos uma análise de subgrupo em pacientes com EDSS $\leq 3,0$ e com EDSS > 3, para avaliar o impacto no tratamento, considerando-se o grau de incapacidade neurológica. Resultados: 0 tratamento com natalizumabe, por pelo menos um ano, reduziu a aRR em $91 \%$, assim como melhorou a incapacidade neurológica. Em pacientes com EDSS $\leq 3,0$ observamos um impacto maior do tratamento na incapacidade neurológica, reduzindo sua progressão em 51\%, durante o período do estudo. O tratamento com natalizumabe é seguro, porém um paciente desenvolveu leucoencefalopatia multifocal progressiva. Conclusão: 0 tratamento com natalizumabe, em terceira linha terapêutica é seguro e eficaz especialmente, em pacientes com incapacidade neurológica leve (EDSS $\leq 3.0)$.

Palavras-chave: natalizumabe, esclerose múltipla, progressão da incapacidade, taxa de surto.

Multiple sclerosis (MS) is a demyelinating, inflammatory disease of the central nervous system (CNS), presumably with an autoimmune etiopathogenesis. The first line therapies developed for the relapsing-remitting form of MS (RRMS) include disease modifying treatments (DMTs) as interferons (IFNs) beta and glatiramer acetate (GA) and they are known to be partially effective, with 20 - 50\% of treated patients experiencing a relapse or disability progression in a short period of time ${ }^{1}$.

Natalizumab is a humanized monoclonal antibody that blocks the $\alpha-4$ integrin, VLA-4, an adhesion molecule present on leukocytes surface, inhibiting their migration into $\mathrm{CNS}^{2}$. In the pivotal study AFFIRM, natalizumab reduced annualized relapse rate (aRR) by $68 \%$ and the risk of sustained disability progression by $42 \%$ over 2 years ${ }^{2}$. Although patients studied in AFFIRM were mostly treatment naïve RRMS patients, natalizumab is only approved for use in patient that failed treatment with DMTs or have highly active disease. This more restricted use of natalizumab is consequence of safety concerns related to risk of progressive multifocal leukoencephalopathy (PML), a rare but potentially life-threatening

\footnotetext{
${ }^{1}$ Universidade Federal de São Paulo, Escola Paulista de Medicina, Departamento de Neurologia, Sao Paulo SP, Brazil;

${ }^{2}$ Universidade de São Paulo, Faculdade de Medicina, Departamento de Neurologia, Sao Paulo SP, Brazil;

${ }^{3}$ Biogen Idec Inc., Área Medical, Sao Paulo SP, Brazil.

Correspondence: Enedina Maria Lobato de Oliveira; UNIFESP / EPM, Disciplina de Neurologia; Rua Botucatu, 740; 04023-900 São Paulo SP, Brasil;

E-mail: enedina.oliveira@unifesp.br

Conflict of interest: There is no conflict of interest to declare.

Received 10 December 2014; Received in final form 18 April 2015; Accepted 11 May 2015.
} 
condition caused by JC (John Cunningham) virus infection of the brain ${ }^{3}$.

In addition to AFFIRM study, several post marketing observational (real life) studies, were conducted with use of natalizumab in clinical practice as per approved label in patients that failed previous DMTs. These mostly national studies demonstrated that also in this population natalizum$a b$ is proved to be effective and safe ${ }^{4,5,6}$. In Brazil, natalizumab was approved by Brazilian regulatory agency (ANVISA) in 2008 as a monotherapy for patients with RRMS, to prevent relapses and delay disability progression in patients: a) with insufficient response to the first line drugs (ie. DMTs) defined as at least one relapse in the previous year and a minimum of nine T2 lesions or one gadolinium (Gd) enhancing lesion or b) in patients with severe RRMS with rapid evolution, defined as $\geq 2$ disabling relapses in one year associated with an increase on $\mathrm{T} 2$ lesion load or $\geq 1 \mathrm{~T} 1 \mathrm{Gd}$ enhancing lesion on MRI compared to a baseline scan, according to its label.

Natalizumab was made commercially available and included in the national formulary in 2011 and is currently only reimbursed for patients with RRMS with insufficient response to both IFNs beta and GA treatment. Natalizumab is not reimbursed for use in RRMS patients with rapid evolution. As of September 2014, there are more than 1100 Brazilian patients treated with natalizumab ${ }^{15}$.

The objective of this study is to analyze the demographics and clinical characteristics, as well as efficacy and safety profile of natalizumab treatment (used mostly as 3rd line treatment), in Brazilian patients with RRMS followed up for at least 12 months in two tertiary MS clinical centers in São Paulo.

\section{METHOD}

A retrospective analysis based on a review of medical records of patients with RRMS (as defined by 2005 McDonald criteria) $^{7}$ treated for at least 12 months with natalizumab (Tysabrì̄ , Biogen Idec, Cambridge, USA) was performed using patients data from two tertiary care center specialized in MS and other demyelinating diseases in São Paulo (Department of Neurology, Federal University of Sao Paulo - UNIFESP, and Department of Neurology, School of Medicine, University of São Paulo - USP). Patients treated for less than 12 months were not included, therefore, patients with any severe reaction, as per physician judgement, who had the medication withdrawn, at any time, before completing 12 months of treatment were excluded from the analysis.

The criteria for choosing natalizumab as a second or third line therapy was at the attending physician's discretion but treatment failure was defined as: at least one relapse (corticoid treatment required) in the previous year and the presence of new lesions, either T2 (minimum two) or T1 with gadolinium enhancement (minimum one). Also, natalizumab treatment could have been initiated for an aggressive disease, defined as two or more relapse within a year and a sustained increase in the Expanded Disability Status Scale (EDSS) score of at least 1 point in the previous year.

Only clinical variables were included in the analysis such as age, gender, disease duration previous to natalizumab treatment, disease activity measured by annualized relapse rate (aRR) and disease progression measured by EDSS and progression index (PI), which is calculated by dividing the EDSS by disease duration time ${ }^{8}$. We evaluated the effect of natalizumab treatment on disability and disease progression (EDSS and PI, respectively) as well as on aRR after at least 12 months of natalizumab treatment. We also performed a subgroup analysis evaluating the efficacy of natalizumab in patients with EDSS $\leq 3.0 v s$ patients with EDSS $>3.0$. Since MRI parameters were not available for all patients, an MRI analysis of natalizumab treatment was not performed.

Statistical analysis was performed using Microsot Excel ${ }^{\circ}$ software. Paired Student $t$ test was used for comparing mean aRR, EDSS scores and PI, before and after natalizumab treatment. Data is presented as mean \pm standard deviation and significance was set as a $\mathrm{p}<0.05$.

This work was approved by each institutional IRB and at UNIFESP is part of an ongoing epidemiological study approved in 2013.

\section{RESULTS}

We identified 75 patients that were on natalizumab treatment for at least 12 months, between December 2008 and March 2014. Seventy four patients had RRMS and one had a progressive course (note: currently natalizumab is not approved for treatment of progressive forms of MS). The majority $(77 \%)$ of patients was females with a mean ( \pm standard deviation (SD)) age of $36.39 \pm 8.64$ years; mean disease duration of $11.84 \pm 7.39$ years and median EDSS score of 4 . The clinical characteristics of all 75 patients are summarized in Table 1.

Natalizumab treatment was implemented to 74 (98.6\%) patients due to treatment failure. Fifty patients failed two DMDs (one interferon beta formulation and glatiramer), 24 have failed either an interferon beta formulation, or glatiramer or cyclophosphamide before natalizumab treatment. Overall $40(53.3 \%)$ patients were treated with immunosuppressant prior to natalizumab. Only one patient with aggressive disease was treated with natalizumab as a first line therapy

Patients received a median of 24 infusions. Twenty-eight patients (37\%) received more than 24 infusions and 47 between 12 - 24 infusions. Treatment with natalizumab was effective in reducing the mean aRR in $91 \%$, from $2.45 \pm 1.86$ in the previous year before treatment to $0.26 \pm 0.58$ over the follow up period (Table 2). Also, during one year of follow up, a total of 61 patients didn't experience any relapse, 1 relapse occurred in 11 patients and 2 relapses were reported by 3 patients (Figure). 
Table 1. Demographic and clinical characteristics of patients with MS at baseline.

\begin{tabular}{|c|c|}
\hline Patients, $\mathrm{n}$ & 75 \\
\hline \multicolumn{2}{|l|}{ Age, years } \\
\hline Mean \pm SD & $36.39 \pm 8.64$ \\
\hline Median (range) & $36(20-55)$ \\
\hline \multicolumn{2}{|l|}{ Gender, n (\%) } \\
\hline Male & $17(22.7)$ \\
\hline Female & $58(77.3)$ \\
\hline \multicolumn{2}{|l|}{ MS disease duration, years } \\
\hline Mean \pm SD & $11.84 \pm 7.39$ \\
\hline Median (range) & $11(3-42)$ \\
\hline \multicolumn{2}{|l|}{ aRR before natalizumab } \\
\hline Mean \pm SD & $2.45 \pm 1.86$ \\
\hline Median (range) & $2(0-10)$ \\
\hline \multicolumn{2}{|l|}{ EDSS score } \\
\hline Mean $\pm S D$ & $4.15 \pm 1.72$ \\
\hline Median (range) & $4(1-6.5)$ \\
\hline \multicolumn{2}{|l|}{ Progression Index } \\
\hline Mean \pm SD & $0.616 \pm 0.485$ \\
\hline Median (range) & $0.469(0-3.0)$ \\
\hline Patients with EDSS Score $\leq 3.0, \mathrm{n}(\%)$ & $22(29.3)$ \\
\hline Patients with EDSS Score > 3.0, n (\%) & $53(70.7)$ \\
\hline Previous use of immunosuppressant (IS), n (\%) & $40(53.3)$ \\
\hline \multicolumn{2}{|l|}{ Previous use of DMTs (IFNs and/or GA), n (\%) } \\
\hline IFN and GA & $50(66.7)$ \\
\hline IFN or GA & $23(30.7)$ \\
\hline Neither & $2(2.7)$ \\
\hline \multicolumn{2}{|l|}{ JCV antibody status n (\%) } \\
\hline Negative & $54(72)$ \\
\hline Positive & $19(25.3)$ \\
\hline Unknown & $2(2.7)$ \\
\hline
\end{tabular}

MS: multiple sclerosis; SD: standard deviation; EDSS: Expanded Disability Status Scale; IFN: interferon; GA: glatiramer acetate; JCV: John Cummings Virus.

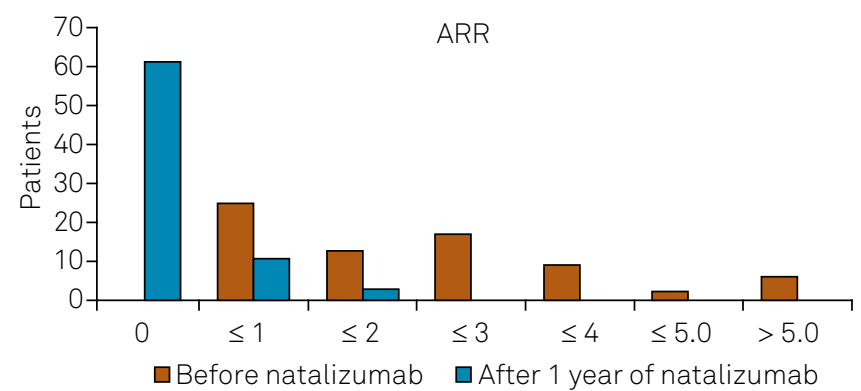

Figure. Number of patients with annualized relapse rate (aRR) reported before and after 1 year of natalizumab treatment.

Apropos of neurological disability, natalizumab treatment showed a significant improvement when one considers EDSS. We observed a mean reduction of 0.65 points in the EDSS score. Since evaluating disability only by EDSS score may not be appropriate due to the fact that it is not a linear scale, we also looked at the progression index (PI). Natalizumab treatment also had a positive impact on PI, slowing down disability progression by $60 \%(\mathrm{p}<0.005)$. Also,
$40 \%$ of patients improved at least 1 point in the EDSS score, over the treatment period.

To investigate whether natalizumab treatment would have a different impact according the severity of neurological disability, we divided the patient population into two different levels of disability: mild (EDSS up to 3.0) and moderate to severe (EDSS >3.0). Natalizumab showed a positive effect on disability, regardless the baseline EDSS, however, patients with an EDSS $\leq$ 3.0 had a $26.1 \%$ reduction in their final EDSS score. Also, when considering disability progression, natalizumab treatment showed a significant impact on PI, with a greater impact in patient with mild disability, over the study period (Table 3).

\section{Safety and tolerability}

Patients received a median of 24 infusions of natalizumab and the medication was safe and well tolerated. Five patients $(6.6 \%)$ reported mild to moderate infusion reactions and up to $85 \%$ of all treated patients never experienced an adverse event. Nonetheless $47 \%$ (35) of all patients, after a median of 24 infusions, withdrew from treatment, mainly due to PML risk, according to physician's decision and based on the following criteria: patients with more than 24 infusions, who have been previously exposed to immunosuppressant and had a John Cummings Virus (JCV) antibody positive status?.

There was one case of PML in a female patient, who had been treated with immunosuppressant previously and had 60 natalizumab infusions. Her anti-JCV status was unknown. Also, one patient presented an Human Papiloma virus (HPV) uveitis. There were no further reports of any other opportunistic infection in the study population.

Table 4 summarizes the reasons for natalizumab withdraw and it is important to highlight that anti-natalizumab antibodies titers were not considered for withdraw, mainly due to the fact that the population presented here was not tested for them.

Regarding to anti-JCV seropositivity, we observed $72 \%$ of patients anti-JCV negative at the beginning of natalizumab treatment, but over the study period, 20 (37\%) patients converted to an anti-JCV positive status, therefore, at the end of the observational period $53 \%$ of all patients were anti-JCV positive, however, since this was a retrospective study, based only on patients' file review we did not calculate the annual conversion rate.

There was one pregnancy during natalizumab treatment. To the extent of our knowledge, treatment was immediately suspended and the offspring was healthy.

\section{DISCUSSION}

This study is a first publication of Brazilian patients with RRMS that were treated for at least one year with natalizumab. It is very important to emphasize how different this population is from the AFFIRM trial'2. The majority of patients included in this study was not naïve and has been exposed to different treatments, including aggressive 
Table 2. aRR, EDSS and PI - before and after natalizumab treatment.

\begin{tabular}{lccc} 
& Before natalizumab & Over 1 year of treatment & $p$-values \\
\hline Mean aRR & $2.45 \pm 1.86(n=75)$ & $0.26 \pm 0.58(n=75)$ & $<0.005$ \\
Mean EDSS score & $4.22 \pm 1.80(n=75)$ & $3.56 \pm 2.16(n=75)$ & $<0.005$ \\
Mean PI & $0.616 \pm 0.485(n=75)$ & $0.367 \pm 0.274(n=75)$ & $<0.005$ \\
\hline
\end{tabular}

aRR: annualized relapse rate; EDSS: Expanded Disability Status Scale; PI: progression index.

Table 3. Subgroup analysis by baseline EDSS score.

\begin{tabular}{lcccc}
\hline & Before natalizumab & After natalizumab & p-values & Percentage of reduction \\
\hline Mean EDSS score (baseline score $\leq 3.0)$ & $2.0 \pm 0.83(n=22)$ & $1.48 \pm 1.01(n=22)$ & $<0.005$ & $26.1 \%$ \\
Mean EDSS score (baseline score $>3.0)$ & $5.05 \pm 1.07(n=53)$ & $4.34 \pm 1.53(n=53)$ & $<0.005$ & $14.0 \%$ \\
Mean PI (baseline score $\leq 3.0)$ & $0.38 \pm 0.28(n=22)$ & $0.19 \pm 0.15(n=22)$ & $<0.005$ & $51.1 \%$ \\
Mean PI (baseline score $>$ 3.0) & $0.71 \pm 0.52(n=53)$ & $0.44 \pm 0.28(n=53)$ & $<0.005$ & $38.0 \%$ \\
\hline
\end{tabular}

EDSS: Expanded Disability Status Scale; PI: progression index.

Table 4. Reasons for natalizumab withdraw.

\begin{tabular}{lcc}
\hline Reason for withdraw & $\mathrm{n}$ & $\%$ \\
\hline PML risk* & 20 & $57.1 \%$ \\
Patients' request & 6 & $17.1 \%$ \\
Vulvar Cancer & 1 & $2.9 \%$ \\
Poor tolerability§ & 1 & $2.9 \%$ \\
Pregnancy & 1 & $2.9 \%$ \\
PML & 1 & $2.9 \%$ \\
Not MS & 1 & $2.9 \%$ \\
Disease stability & 1 & $2.9 \%$ \\
HPV uveitis & 1 & $2.9 \%$ \\
PPMS & 1 & $2.9 \%$ \\
SPMS & 1 & $2.9 \%$ \\
Total & 1 & $100.0 \%$ \\
\hline
\end{tabular}

MS: multiple sclerosis; PML: progressive multifocal

leukoencephalopathy; HPV: Human papiloma virus; SPMS:

Secondary progressive multiple sclerosis.

*As defined by attending physician and based on previous

immunosuppressant exposure and length of natalizumab treatment.

§ As defined by treating attending physician based on infusion

reaction. $¥$ According to attending physician’s notes on patient file.

immunosuppression. In our opinion, such population reflects better the "real life" type of patients in Brazil, since the use of Natalizumab in local clinical practice (reimbursement guidelines) is restricted to RRMS patients that failed IFN beta treatments as well as glatiramer acetate resulting in a treatment scenario with patients with more accumulated disability.

Prior to treatment with natalizumab, the population in the AFFIRM trial had a mean aRR of 1.5 and a mean EDSS of 2.3 with approximately $40 \%$ of patients with $\geq 2$ relapse in the preceding year. Also, in this pivotal trial the overall disease duration was 5 years. Although not comparable, the population we describe seems to have a more aggressive disease with an aRR of 2.45 and a mean EDSS of 4.2, as well as longer disease duration. We were not able to perform a subgroup analysis based on relapse rate; nonetheless, the overall efficacy results were impressive with a $91 \%$ reduction in aRR. Similar results were shown by Hutchinson et al..$^{10}$ in a subgroup analysis of patients with a highly active disease from the AFFIRM and SENTINEL trials.

Natalizumab improved EDSS score with a mean reduction greater than 0.5 point in the whole population, and $40 \%$ of our patients indeed improved theirs EDSS score in at least one point. It is important to emphasize that, when comparing the effect of treatment within different ranges of disability, patients with an EDSS $\leq 3.0$ showed a better outcome, with a 26\% reduction in the final EDSS score. Likewise, natalizumab proved to slow down disease progression as measured by the progression index. Philips et al..$^{11}$ in a recent study demonstrated that natalizumab treatment was associated with a sustained reduction in EDSS scores, especially in patients with EDSS $\geq 2$. Thus, it seems that natalizumab treatment is able to halt disease progression. However, despite suggesting a more favorable outcome in patients with EDSS $\leq 3.0$, we should interpret these results with caution.

We were not able to estimate the proportion of disease free patients ${ }^{12}$ in our cohort since we faced the difficulties in gathering data, common to most retrospective studies. Nevertheless, $81 \%$ of our patients experienced no relapse during natalizumab treatment and we observed a sustained improvement of disability. In agreement with our findings, Putzki et al. ${ }^{4}$ also showed that approximately $80 \%$ of patients remain relapse free while in treatment and $89 \%$ were disease progression free in a study analyzing the efficacy of natalizumab as a second line therapy in Germany.

Recently, Fernandez et al. reported on the Spanish experience with natalizumab ${ }^{6}$. They demonstrated that, in real life, natalizumab reduced aRR from 2.0 to 0.0 and improved EDSS, in at least 0.5 point. The magnitude of the reduction in aRR and EDSS progression, with natalizumab treatment, in the Spanish cohort is as expressive as the one we describe. But, it is important to highlight that this Brazilian cohort seems to have patients with more aggressive disease, with a higher median aRR (2.45 vs 2.0) and also a higher baseline EDSS (4.2 vs 3.7).

Natalizumab was well tolerated, and no major adverse event was observed within 12 months of treatment. The 
discontinuation rate described in this study reflects the longer treatment period compared with others real life studies, since we gathered information for 6 years and the median infusion number in our series is 24 . So, one would expect that nearly half of our patients withdrew from treatment, at the end of this period. Indeed, most patients (57.1\%) decided to interrupt treatment due to PML risk, but $85 \%$ of our patients never experienced any adverse events. Similar results were found by Fragoso et al. in a recent paper analyzing natalizumab safety and tolerability reports during over more than 1000 infusions $^{13}$. It is important to note that the only PML case happened after 60 infusions in a patient who has been treated with immunosuppressant previously.

Regarding anti-JCV seropositivity, it has been shown frequencies of JCV antibodies, in general population, between $50 \%$ and $60 \%$, with higher prevalence in men than in women ${ }^{9,14,15}$. However, it is interesting to highlight that at the beginning of natalizumab treatment, anti-JCV seropositivity was lower in our patients than expected, since $75 \%$ of this cohort had a negative anti-JCV status. This may reflect a selection bias for natalizumab treatment, in order to minimize PML risk. Nonetheless, at the end of the observational period, $53 \%$ of our patients were anti-JCV positive which reinforces the need for frequent testing in order to properly assess PML risk during treatment. Also, it is noteworthy to emphasize that PML monitoring with MRI every
6 months is mandatory for those patients anti-JCV positive with more than 24 months of treatment, especially if they have been previously treated with any immunosuppressant. And indeed, all patients anti-JCV positive who decided to go on natalizumab treatment are under a rigorous follow up schedule, with MRI screening every 6 months.

This is a large Brazilian study showing that natalizumab is an effective treatment for multiple sclerosis in a real life scenario. However, one should take into account that this is a retrospective study that gathered data from two different centers with possibly different selection criteria for natalizumab treatment. But, in spite of having a heterogeneous patient population, we could demonstrate the effect of natalizumab treatment on annual relapse rate and disease progression and demonstrate its safety as a third line therapy. The impact of natalizumab treatment on patients with mild neurological disability should prompt neurologists to considering switching treatment at the early stages of treatment failure.

\section{ACKNOWLEDGEMENT}

The authors would like to thankDr.Diogo Amarante(Biogen Idec Brazil) for helpful discussions about the manuscript and Renato Oliveira (Biogen Idec Brazil), for statistical analysis.

\section{References}

1. Río J, Comabella M, Montalban X. Predicting responders to therapies for multiple sclerosis. Nat Rev Neurol. 2009;5(10):553-60. doi:10.1038/nrneurol.2009.139

2. Polman $\mathrm{CH}, \mathrm{O}$ 'Connor PW, Havrdova E, Hutchinson M, Kappos $\mathrm{L}$, Miller DH et al. A randomized, placebo-controlled trial of natalizumab for relapsing multiple sclerosis. N Engl J Med. 2006;354(9):899-910. doi:10.1056/NEJMoa044397

3. Brew BJ, Davies NW, Cinque P, Clifford DB, Nath A. Progressive multifocal leukoencephalopathy and other forms of JC virus disease. Nat Rev Neurol. 2010;6(12):667-79. doi:10.1038/nrneurol.2010.164

4. Putzki N, Yaldizli O, Mäurer M, Cursiefen S, Kuckert S, Klawe $\mathrm{C}$ et al. Efficacy of natalizumab in second line therapy of relapsing-remitting multiple sclerosis: results from a multi-center study in German speaking countries. Eur J Neurol. 2010;17(1):31-7. doi:10.1111/j.1468-1331.2009.02728.x

5. Castillo-Trivino T, Mowry EM, Gajofatto A, Chabas D, Crabtree-Hartman E, Cree BA et al. Switching multiple sclerosis patients with breakthrough disease to second-line therapy. PLoS One.2011;6(2):e16664. doi:10.1371/journal.pone.0016664

6. Fernández O, Oreja-Guevara C, Arroyo R, Izquierdo G, Pérez JL, Montalban X. Natalizumab treatment of multiple sclerosis in Spain: results of an extensive observational study. J Neurol. 2012;259(9):1814-23. doi:10.1007/s00415-012-6414-9

7. Polman CH, Reingold SC, Edan G, Filippi M, Hartung HP, Kappos Let al. Diagnostic criteria for multiple sclerosis: 2005 revisions to the "McDonald Criteria”.Ann Neurol. 2005;58(6):840-6. doi:10.1002/ana.20703

8. Bichuetti DB, Oliveira EM, Souza NA, Rivero RL, Gabbai AA. Neuromyelitis optica in Brazil: a study on clinical and prognostic factors. Mult Scler. 2009;15(5):613-9. doi:10.1177/1352458508101935
9. Sørensen PS, Bertolotto A, Edan G, Giovannoni G, Gold R, Havrdova E et al. Risk stratification for progressive multifocal leukoencephalopathy in patients treated with natalizumab. Mult Scler. 2012;18(2):143-52. doi:10.1177/1352458511435105

10. Hutchinson M, Kappos L, Calabresi PA, Confavreux C, Giovannoni G, Galetta SL et al. The efficacy of natalizumab in patients with relapsing multiple sclerosis: subgroup analyses of AFFIRM and SENTINEL.J Neurol. 2009;256(3):405-15. doi:10.1007/s00415-009-0093-1

11. Phillips JT, Giovannoni G, Lublin FD, O'Connor PW, Polman CH, Willoughby E et al. Sustained improvement in Expanded Disability Status Scale as a new efficacy measure of neurological change in multiple sclerosis: treatment effects with natalizumab in patients with relapsing multiple sclerosis. Mult Scler. 2011;17(8):970-9. doi:10.1177/1352458511399611

12. Havrdova E, Galetta S, Hutchinson M, Stefoski D, Bates D, Polman $\mathrm{CH}$ et al. Effect of natalizumab on clinical and radiological disease activity in multiple sclerosis: a retrospective analysis of the Natalizumab Safety and Efficacy in Relapsing-Remitting Multiple Sclerosis (AFFIRM) study. Lancet Neurol. 2009;8(3):254-60. doi:10.1016/S1474-4422(09)70021-3

13. Fragoso YD, Alves-Leon SV, Arruda WO, Carvalho MJ, Comini-Frota ER, Corrêa EC et al. Natalizumab adverse events are rare in patients with multiple sclerosis. Arq Neuropsiquiatr. 2013;71(3):137-41. doi:10.1590/S0004-282X2013000300002

14. Olsson T, Achiron A, Alfredsson L, Berger T, Brassat D, Chan A et al. Anti-JC virus antibody prevalence in a multinational multiple sclerosis cohort. Mult Scler. 2013;19(11):1533-8. doi:10.1177/1352458513477925

15. Ministério da Saúde (BR). DATASUS- Portal da Sáude - Ministérioa da Sáude. [acesso 2014 Dec 12]. Available from: http://www2.datasus.gov. $\mathrm{br} /$ DATASUS/index.php?area $=0901 \&$ item $=1 \&$ acao $=22 \& \mathrm{pad}=31655$ 